\title{
Demographic effects on fruit set in the dioecious shrub Canada buffaloberry (Shepherdia canadensis)
}

The effects of pollen limitation on reproductive success in plants have been well-documented using pollen supplementation experiments. However, the role of local demographics in determining pollen limitation, particularly in terms of the additive and interactive effects of pollen availability and competition are not well known. We measured fruit set in the dioecious shrub Canada buffaloberry (Shepherdia canadensis) in Central Alberta, Canada to evaluate whether local demographics measured at three spatial scales $\left(25,50\right.$, and $\left.100 \mathrm{~m}^{2}\right)$ affect fruit set in buffaloberry. We test whether density-dependence (population density), pollen donor (measured as male density, distance to nearest male plant and size of nearest male plant), female competitor (measured as female density and distance to nearest female plant), or the combined pollen donor and competitor hypotheses best explain natural variations in fruit set for a population of Canada buffaloberry. Support was highest for the combined pollen donor and competitor hypothesis at an intermediate spatial scale of $50 \mathrm{~m}^{2}$. Proportion fruit set increased with male shrub density (pollen donors) and decreased with female shrub density (pollen competitors). This illustrates that access to male shrubs within a $3.99 \mathrm{~m}$ radius affects pollen availability to female shrubs, while nearby females compete intra-specifically for pollen. 


\section{Authors:}

2 Kate M. Johnson ${ }^{1 *} \&$ Scott E. Nielsen ${ }^{2}$

\section{Affiliations:}

$4 \quad{ }^{1}$ Centre for Applied Conservation Research, University of British Columbia, Vancouver, B.C.,

5 Canada

$6 \quad{ }^{2}$ Department of Renewable Resources, University of Alberta, Edmonton, Alberta, Canada

7 *Correspondence to: kate1@ualberta.ca

\section{Introduction}


9 Fruit set is commonly limited by pollen availability, particularly in dioecious species due to the

10 isolation of male and female reproductive organs (Burd 1994; Knight 2005). Because dioecious

11 plants tend to rely on wind or small, generalist insects for pollination (Bawa 1990, Armstrong \&

12 Irvine 1989), their reproductive success is dependent on the distribution and density of sexes

13 within the range of insect pollinators or wind transport (House 1992). Demographic factors have

14 been shown to play a role in determining fruit set through regulation of the quantity and quality

15 of pollen available to females (House 1992; Kunin 1993; Knight 2005). Pollen quantity is known

16 to be related to distance to nearest conspecific male plant (Kay et al. 1984; De Jong, Batenburg \&

17 Klinkhamer 2005; Wang, et al. 2013), local male density (House 1992) and population sex ratio

18 (Osunkoya 1999). However, the role of female competitors in regulating pollen availability, as

19 well as the additive effects of pollen donation from males and competition from females, has

20 received much less attention.

21 Buffaloberry is a shade intolerant (Humbert et al. 2007), nitrogen-fixing (Hendrickson \& Burgess

22 1989; McCray-Batzli et al. 2004; Rhoades et al. 2008) dioecious shrub common to disturbed

23 boreal and temperate montane forests of western North America (Stringer \& LaRoi 1970; LaRoi

$24 \&$ Hnatiuk 1980). Shrubs heights (widths are often similar) range between 0.9 to $3.9 \mathrm{~m}$ (Bormann

25 1988), although in Alberta they are rarely over $2 \mathrm{~m}$. Fruit production in buffaloberry is inversely

26 related to canopy cover (Hamer 1996; Nielsen et al. 2004), with inter-annual variation in fruit

27 explained primarily by the previous year's midsummer rainfall suggesting that climate affects the

28 development of flower primordium (Krebs et al. 2009). Plants flower early in the spring, among

29 the earliest of plants in the region, shortly after the soil thaws and before the forest canopy leafs

30 out (Figure 1). Buffaloberry is pollinated nearly entirely by dipterans (97\%), the majority of

31 which are in the Syrphidae and Empididae families (Borkent \& Harder 2007), with

32 Hymenopterans and Hemipterans also known to pollinate buffaloberry (Lewis 1990). Male 
33 buffaloberry flowers offer both pollen and nectar rewards to potential pollinators, while female

34 flowers only produce nectar (Mosquin 1971; Lewis 1990). Insect pollinators of buffaloberry visit

35 each sex at equal rates, possibly due to an inability to discriminate between flowers (Borkent \&

36 Harder 2007). Pollinators visit an average of 6 flowers per plant, spend $>9$ seconds at each

37 flower, and have a 25\% re-visitation rate (Borkent \& Harder 2007). This relationship suggests

38 that the reproductive success of buffaloberry is pollen-limited due to a deficiency in pollinator 39 visits.

40 Here we use buffaloberry as a model species to examine how pollen donor (male) and pollen

41 competitors (female) affect fruit set in a dioecious species. We hypothesize that a male-biased

42 population density should produce higher fruit set for any nearby female shrub due to increased

43 pollen availability (pollen donor hypothesis), while a female-biased population density should

44 increase competition for pollen and thus decrease fruit set for any given female plant (female

45 competitor hypothesis). We also test the pollen donor hypothesis as distance to nearest male plant

46 and the female competitor hypothesis as distance to nearest female plant. These could be

47 considered simple pollen donor and competitor hypotheses as commonly measured in the

48 literature. Pollen donor and female competitor hypotheses are not, however, mutually exclusive.

49 Both should affect fruit set in dioecious species and we compare this combined factor hypothesis

50 with the pollen donor and female competitor hypotheses. We consider the pollen donor and

51 female competitor hypothesis as either an additive effect of pollen donors and female competitors

52 (measured as both distance to nearest plant and as local density) or an interactive effect of male

53 and female-biased population, which we interpret as the sex ratio of the population. We also

54 compare these hypotheses against a null model of equal fruit set regardless of local demography,

55 a simple density-dependent hypothesis based on total population size ignoring local sex-biases,

56 and a male size hypothesis that considers the distance and size of the nearest pollen source. We 
57 examine these hypotheses by measuring fruit set for a natural population of buffaloberry in

58 Central Alberta, Canada.

\section{Materials and methods}

60 Sixty buffaloberry shrubs were randomly selected in Terwillegar Park in Edmonton, Alberta,

61 marked with a double-faced aluminum tag wired to one stem at the base of the shrub, and

62 monitored for flowering and fruit set between 8 May and 22 June 2012. Terwillegar Park is a 174

63 hectare natural area located along the North Saskatchewan River in the southwest part of

64 Edmonton $\left(53.48071^{\circ} \mathrm{N}, 113.60785^{\circ} \mathrm{W}\right)$. The middle of the park is an open off-leash dog area

65 that is surrounded by natural vegetation with minimum management (City of Edmonton 2009).

66 Buffaloberry shrubs in the area are common along forest edges and in semi-open deciduous

67 forests of balsam popular (Populus balsamifera) and trembling aspen (Populus tremuloides).

68 Total population size in the park is likely $>5,000$ shrubs. Plants were selected to be representative

69 of the conditions of the study area, ranging from shrubs occurring within low density open habitat

70 to shrubs occurring in more dense edge and forested habitat. In any one location a female plant

71 was randomly selected by throwing a stake and then selecting the nearest female shrub. Focal

72 females were located a minimum of $11.28 \mathrm{~m}$ away from each other to ensure there was no

73 overlap of neighboring shrubs at the largest spatial scale measured (5.64 m radius from focal

74 plant). Shrub density $\left(100 \mathrm{~m}^{2}\right)$ ranged from 0-34 reproductive adults around the focal plant, with

75 a mean of $10.42( \pm 1.20)$. Our sample population was marginally female-biased at all spatial

76 scales measured but not significantly different (Table 1).

77 We used a natural experiment to test pollen donor and female competition hypotheses by

78 examining variation in fruit set among shrubs within an open pollination system following other

79 studies of fruit set in dioecious plants (Armstrong \& Irvine 1989; House 1992; Wang et al. 2013). 
80 Although experimental hand pollination experiments (pollinator restriction [bagging] would be

81 unnecessary since it is a dioecious species) could be used to address pollen limitations, we were

82 interested here in examining how local demographic effects influenced fruit set within the same

83 population and year of fruiting.

84 Due to the large number of potential flowers present on an individual shrub (many 1000s), a

85 subsample of flowers was counted to measure initial flower production and thereafter fruit set

86 (e.g. Bowers 2009; Khanizadeh 1989). Specifically, we systematically sampled from each of the

8760 focal female shrubs four branch segments approximately $30 \mathrm{~cm}$ in length by randomly

88 selecting one branch from each the four cardinal directions. Sampled branch segment were

89 marked with a Sharpie ${ }^{\circledR}$ pen by encircling the branch stem $30 \mathrm{~cm}$ from the tip of the branch with

90 a 'permanent mark'. The number of flowers on each branch segment was counted twice. First

91 between 8 and 10 May and recounted again between 23 and 24 May to ensure full flower counts

92 since phenology of shrubs varied slightly and due to later than normal spring conditions. Because

93 male buffaloberry flowers earlier and longer it generally overlaps with all female flowering.

94 Maximum number of flowers observed among either of the two counts was used as the total

95 number of flowers per sampled branch to ensure flowers were counted during the period of

96 overlap. Because fruit ripening begins here in early July, we visited all shrubs between 22 and 28

97 of June as the color of fruit began to change color allowing easier counts of the number of fruit

98 per marked branch. Fruit set for each shrub was defined as the proportion of total flowers with

99 fruit based on the number of fruit to flowers counted across all four branch segments (initial

100 analyses revealed no differences among branch orientations). Based on general observations of

101 fruit production in the prior five years, fruit abundance in Terwillegar Park in 2012 appeared to

102 be average (Nielsen, personal observation). 
103 We quantified population demography of local buffaloberry populations around each marked

104 female shrub at three spatial scales: $25 \mathrm{~m}^{2}$ (2.82 m radius), $50 \mathrm{~m}^{2}$ (3.99 m radius), and $100 \mathrm{~m}^{2}$

105 (5.64 m radius). Prior evidence indicates that the insect pollinators of buffaloberry are short-

106 distance fliers (Borkent \& Harder 2007), but because we were unsure of the range within which

107 pollinators are most active, we bracketed sampling across three scales (the moderate scale

108 appears to be the most predictive suggesting that the scale selected was representative of the scale

109 of pollination effects). Distances to all neighboring shrubs (by sex) were measured using a Haglöf

110 DME 201 Cruiser (Långsele, Sweden) with the transponder centered on the marked plant and the

111 electronic receiver held over the center of all other surrounding shrubs to measure distance to the

112 marked female shrub out to a maximum of a $5.64 \mathrm{~m}$ radius. In addition to sex-specific densities,

113 distance to nearest male and female shrub was measured as a simple test of the pollen donor and

114 female competitor hypotheses (minimum distance) as this is commonly used in the literature.

115 This included measurements beyond $5.64 \mathrm{~m}\left(100 \mathrm{~m}^{2}\right)$ in the few cases where shrub density was

116 low enough that no males were present within the largest sampling scale used (5.64 m radius).

117 Ten a priori candidate models were defined for each spatial scale $\left(25 \mathrm{~m}^{2}, 50 \mathrm{~m}^{2}\right.$, and $\left.100 \mathrm{~m}^{2}\right)$

118 based on the following hypotheses (Table 2): (0) null model of equal (mean) fruit set among

119 plants (.); (1) simple pollen donor hypothesis measured as distance to nearest male shrub or

120 source of pollen ( $\left.-\widehat{O}^{\text {dist }}\right)$; (1a) nearest male and size of nearest male hypothesis measured as the

121 distance and size of the nearest pollen source $\left(-\hat{O}_{\text {dist }}+\hat{O}_{\text {size }}\right)$; (2) nearest male and female

122 competitor hypothesis measured as the distance to nearest male shrub and female shrub density (-

$\left.123 \hat{O}_{\text {dist }}-Q_{D}\right)$; (3) simple pollen competitor hypothesis measured as distance to nearest female shrub

124 or female competitor $\left(++_{\text {dist }}\right)$; (4) nearest female and pollen donor hypothesis measured as

125 distance to nearest female shrub and male density $\left(++_{+ \text {dist }}+\hat{O}_{D}\right)(5)$ density-dependent hypothesis

126 measured as total population density of reproductive shrubs $(+D) ;(6)$ pollen donor hypothesis 
127 measured as male shrub density $\left(+\hat{O}_{D}\right)$; (7) pollen competitor hypothesis measured as female

128 shrub density $\left(-q_{D}\right)$; (8) pollen donor and pollen competitor hypotheses combined additively

$129\left(+\hat{O}_{D}-\hat{+}_{D}\right)$ or (9) pollen donor and pollen competitor hypotheses (sex ratio) combined

130 multiplicatively $\left(+\hat{O}_{D} *-Q_{D}\right)$. We used the interaction between density of individual sexes rather

131 than a ratio of males to females to represent sex ratio to avoid reducing our sample size as several

132 plots contained no plants within a spatial scale and these observations would have to be excluded

133 in a sex ratio model (inferences were similar when analyzing a smaller set of the data using a

134 male bias variable [male - female shrub density] as a predictor). We predicted the direction of the

135 response in fruit set for each hypothesis as indicated by the - or + symbols representing negative

136 or positive effects on fruit set respectively. Specific to our hypotheses, we expected fruit set to

137 decrease with distance to nearest male shrub $(-\hat{O}$ dist $)$, and increase with the size of the nearest

138 male $\left(+\hat{O}_{\text {size }}\right)$ since that is the source of pollen. Likewise fruit set was expected to increase with

139 population density $(+D)$, and especially for male density $\left(+{ }^{\lambda} D\right)$, since again this would be the

140 source of pollen. Conversely, we expected fruit set to increase with distance to nearest female

141 shrub $\left(+q_{d i s t}\right)$ and decrease with local female shrub density since they would be competing for

142 pollen $\left(-q_{D}\right)$. We predicted an additive effect of male and female shrub density or distance

$143\left(+\hat{O}_{D} /-\hat{O}_{\text {dist }}-Q_{D} /+Q_{\text {dist }}\right)$ on fruit set with male density and female distance positively related to

144 fruit set and female density and male distance negatively related to fruit set, but not necessarily at

145 the same rate. Finally, we expected an interaction between male and female density $\left(+\widehat{O}_{D}{ }^{*}-Q_{D}\right)$

146 above what could be predicted by the additive model, indicating the importance of the local

147 population's sex ratio.

148 To test support for these hypotheses, we modeled proportion fruit set of buffaloberry based on our 149 hypothesized factors using a generalized linear model (GLM) using STATA 12.1 with a beta 150 distribution and logit link (Ferrari \& Cribari-Neto 2004). Collinearity (Pearson correlations > 
$1510.7 \mid)$ was checked among variables within each model with no problems found. Total number of

152 flowers per sampled length was multiplied by shrub size to represent total flower production,

153 which is often positively correlated with fruit set (Osunkoya 1999; Somanathan \& Borges 1999)

154 and was a significant predictor of fruit set. This variable was included as a covariate in all

155 models. Initial analyses found little effect of environmental variation (canopy cover, broad habitat

156 class and soil electrical conductivity) and thus were not included. Models were ranked for support

157 using the small sample size corrected Akaike's Information Criterion $\left(\mathrm{AIC}_{\mathrm{c}}\right)$ where smaller $\mathrm{AIC}_{\mathrm{c}}$

158 values indicate more support for the model given the data and models tested (Burnham \&

159 Anderson 2004). Model parameters were estimated for the top $\mathrm{AIC}_{\mathrm{c}}$-selected model ( $\operatorname{raw} \beta$

160 coefficients and predicted total response in proportion fruit set when independent predictor

161 variables where changed from observed minimum to maximum values) with predictions graphed 162 to assist with interpretation.

\section{Results}

164 The most supported candidate models explaining fruit set in buffaloberry were the pollen donor

165 and competitor hypothesis $\left(+\hat{O}_{D}-Q_{D}\right)$ at the $50 \mathrm{~m}^{2}$ scale and the pollen donor hypothesis again at

166 the $50 \mathrm{~m}^{2}$ scale $\left(+\hat{O}^{2}\right.$ ) (Akaike weights, $w_{i}=0.244$ and 0.089 respectively; Table 3 ) thus

167 supporting both the pollen donor and pollen competitor hypotheses. These models were followed

168 by the pollen donor and competitor hypothesis at the $100 \mathrm{~m}^{2}$ scale $\left(+\hat{O}_{D_{m}}-Q_{D_{m}}\right)\left(w_{i}=0.083\right.$; Table

$1693)$ and the sex ratio hypothesis at the $50 \mathrm{~m}^{2}$ scale $\left(+\hat{O}_{D_{m}} *-Q_{D_{m}}\right)\left(w_{i}=0.080\right.$; Table 3$)$. The null

170 model (.) of equal fruit set among shrubs, regardless of local demography, was 4.28 times less

171 supported (evidence ratio of Akaike weights, $\left.w_{i}\right)$ than our top $\mathrm{AIC}_{\mathrm{c}}$ model $\left(\Delta \mathrm{AIC}_{\mathrm{c}}=2.9\right)$. All

172 other models were less supported than the null model $\left(\Delta \mathrm{AIC}_{\mathrm{c}}=3.5-6.5\right)$, but still plausible. This

173 included the simple pollen donor hypothesis that was measured as distance to nearest male plant

$174\left(\Delta \mathrm{AIC}_{\mathrm{c}}=3.5\right)$, suggesting that density is a better indicator of available pollen than distance to 
175 nearest male. A simple density-dependence model $(+D)$ measuring local shrub density also had

176 less support than the null model, illustrating the importance of sex-specific demography and thus

177 opposite effects of sexes on fruit set. The pollen competitor hypothesis $\left(-q_{D}\right)$ alone had much less

178 support $\left(\Delta \mathrm{AIC}_{\mathrm{c}}=5.1\right.$ at $100 \mathrm{~m}^{2}$ scale; Table 3$)$, despite being present as a variable in the top

179 supported model which included male density $\left(+\hat{O}_{D}-q_{D}\right)$. Nearest female and pollen donor

180 hypothesis $\left(+Q_{d i s t}+\widehat{O}_{D}\right)$, as well as the nearest male and female competitor hypothesis $\left(-\hat{O}^{d i s t}-\right.$

$\left.181 q_{D}\right)$, both had low support indicating that density is still a better predictor of fruit set than

182 distance and density combined. Indeed, the nearest female and pollen donor hypothesis at the 100

$183 \mathrm{~m}^{2}$ scale was the least supported model tested $(\Delta \mathrm{AIC} c=6.5$; Table 3$)$. Nearest male and size of

184 nearest male $\left(-\hat{O}_{\text {dist }}+\hat{O}_{\text {size }}\right)$ was the second least supported hypothesis $\left(\Delta \mathrm{AIC}_{\mathrm{c}}=5.9\right.$; Table 3$)$,

185 suggesting that the size of the nearest male does not make the simple pollen donor hypothesis a

186 better predictor of fruit set. When considering the spatial scale at which fruit set was most

187 affected by surrounding shrubs, the $50 \mathrm{~m}^{2}$ scale ( $3.99 \mathrm{~m}$ radius) was consistently more supported

188 than the other two spatial scales tested.

189 Using the top supported model representing the pollen donor and pollen competitor hypothesis

$190\left(+\hat{O}_{D}-Q_{D} 50 \mathrm{~m}^{2}\right)$, proportion fruit set increased by $0.352(\mathrm{SE}=0.123)$ when male shrub density

191 increased from its minimum ( 0 shrubs) to maximum (13 shrubs) value ( $\Delta$ Min to Max; Table 4$)$.

192 This supports the pollen donor hypothesis where access to male shrubs affects pollen availability.

193 Female shrub density, on the other hand, was inversely related to proportion fruit set with

194 proportion fruit set decreasing by $0.221(\mathrm{SE}=0.080)$ when female shrub density increased from

195 its minimum ( 0 shrubs) to maximum ( 15 shubs) value (Table 4$)$ thus also supporting the pollen

196 competitor hypothesis where females compete intra-specifically for pollen. This negative effect

197 on fruit set was, however, evident only after considering pollen donor effects of male shrub

198 density, since there was little support for this effect alone ( $w_{i}=0.019$ at $100 \mathrm{~m}^{2}$ scale; Table 3$)$. 
199 Fruit set was also marginally more affected by the presence of males (pollen donor) than females

200 (pollen competitor) with the highest fruit set occurring when sex bias was skewed heavily

201 towards males (Figure 2). Across the range of the total flower index ( $\Delta$ Min to Max), proportion

202 fruit set decreased by $0.283(\mathrm{SE}=0.065)$ units (Table 4$)$.

\section{Discussion}

204 Although a number of studies have demonstrated a negative effect of plant isolation on fruit set, 205 especially for dioecious plants (Kay et al 1984; House 1992; Steffan-Dewenter et al. 1999; De 206 Jong, Batenburg \& Klinkhamer 2005; Wang et al. 2013), pollen limitation is not considered in 207 terms of the additive or interactive effects of pollen availability (pollen donor) and competition 208 (surrounding female shrubs). We found that density of male and female shrubs at both $50 \mathrm{~m}^{2}$ and $209100 \mathrm{~m}^{2}$ predicted fruit set in buffaloberry better than nearest neighbor measures. Similar to other 210 studies, local male density was significantly more related to fruit set than distance to nearest male 211 (House 1992). Our results may be related to the foraging habits of buffaloberry pollinators, which

212 visit an average of 6 flowers per plant, spend a relatively long time at each flower and revisit

213 flowers frequently, indicating that pollinators are not highly mobile and tend to forage within a

214 small area (Borkent \& Harder 2007), making a high concentration of local pollen important.

215 Local male density was most predictive of fruit set when considered in terms of the additive 216 effect of increased pollen donors and decreased pollen competitors. Our support for the pollen

217 competitor hypothesis contrasts with the findings of Wang et al. (2013) who found no significant

218 effect of female competition on fruit set in the dioecious tree Rhamnus davurica. We show that

219 female density alone is not a good predictor of fruit set unless considered in conjunction with

220 male density, indicating that future assessments of pollen limitation should consider these factors

221 in terms of their additive or multiplicative effects. Distance to nearest female is also not 
222 predictive of fruit set, even when considered with male density, suggesting that density is a better

223 measure of female competition than distance to nearest female. Competition for pollen at high

224 female densities limits the quantity of pollen available to any given female. Because buffaloberry

225 pollinators visit both sexes at equal rates (Borkent \& Harder 2007), pollinators are more likely to

226 have visited a female previously and be carrying less pollen in a population with high female

227 density. In addition to facilitating higher fruit set, females occurring within male-biased

228 populations may experience increased long-term fitness. Females with access to a wider choice of

229 mates could produce a surplus of embryos, which would enable selective abortion of lower

230 quality seeds (Melser \& Klinkhamer 2001). The reproductive advantages attributed to females

231 occurring within male-biased populations may be necessary to compensate for the greater

232 reproductive costs incurred by females that attract seed dispersers with fleshy fruits. Indeed male-

233 biased sex ratios are common in other long-lived dioecious species with biotic seed dispersal and

234 fleshy fruit (Field, Pickup \& Barrett 2012). The marginally higher female-bias of our sample

235 population suggests that reproductive success is at least partly limited by pollen quantity.

236 All demographic factors were most predictive of fruit set at a scale around focal female shrubs of

$23750 \mathrm{~m}^{2}$, likely due to the combined effects of plant distribution and pollinator activity. Similar

238 studies of dioecious species have documented a threshold of isolation below which fruit set is not

239 limited by insufficient pollinator visits (Kay et al. 1984; De Jong, Batenburg \& Klinkhamer

240 2005). It is likely that the high flight costs of generalist pollinators confine pollinator activities to

241 a small area and discourage travel between patches (Klinkhammer et al. 2001). The high number

242 of flowers visited per plant and rate of re-visits (25\%, Borkent \& Harder 2007) indicates

243 pollinator reluctance to leave a patch once they have begun foraging. A lack of support for the

244 smaller $25 \mathrm{~m}^{2}$ scale suggests that plant distribution is also important. At this smaller scale there 
245 may not have been sufficient males to provide the benefits of increased pollen availability and the

246 benefit of pollen donors was therefore not detected.

247 In contrast with similar studies (Osunkoya 1999; Somanathan \& Borges 1999), we found a

248 negative relationship between our index representing total flower production and fruit set.

249 Undiscriminating pollinators may cause large females with many flowers to be at a disadvantage,

250 resulting in more severe pollen limitation and lower reproductive success. The lack of support for

251 the density dependent hypothesis indicates that as well as not biasing visits based on sex or floral

252 productivity, pollinators also do not prefer patches with a higher density of plants. This suggests

253 that the Dipteran pollinators of buffaloberry are opportunistic, and given similar rates of

254 pollinator visitation to males and females, and low and high density patches, females located

255 within male biased populations are least likely to be pollen-limited and will therefore experience

256 higher fruit set.

\section{Conclusion}

258 A male-biased population of buffaloberry surrounding a female shrub (within 3.99 m radius; 50

$259 \mathrm{~m}^{2}$ ) exhibits higher fruit set, supporting both the pollen donor and pollen competitor hypotheses.

260 Although fruit set in buffaloberry was influenced by both male (positively) and female

261 (negatively) shrub density, local male density had a stronger effect on fruit set. This study

262 demonstrates that local demographics affect fruit set through the additive effects of pollen donors

263 and competitors. More research is needed to understand factors affecting flower production and

264 pollinators of buffaloberry.

\section{Acknowledgements}

266 We thank Andrew Braid and Tyler Bateman for their assistance during fieldwork. 


\section{References}

268 Armstrong JE, Irvine AK (1989) Flowering, sex ratios, pollen-ovule ratios, fruit set, and

269 reproductive effort of a dioecious tree, Myristica insipida (Myristicaceae), in two different

$270 \quad$ rain forest communities. Am J Bot 76:74-85

271 Bawa KS (1990) Plant-pollinator interactions in tropical rain forests. Annu Rev of Ecol Syst

$272 \quad 21: 399-422$

273 Borkent CJ, Harder LD (2007) Flies (Diptera) as pollinators of two dioecious plants: behavior 274 and implications for plant mating. Can Entomol 129:235-246

275 Bormann, BT (1988) A masterful scheme: Symbiotic nitrogen-fixing

276 plants of the Pacific Northwest. Univ Washington Arboretum

277 Bulletin 51:10-14.

278 Bowers JE (2009) Branch length mediates flower production and inflorescence architecture of $279 \quad$ Fouquieria splendends (ocotillio). Plant Ecol 186:87-95

280 Burd M (1994) Bateman's Principle and Plant Reproduction: The Role of Pollen Limitation in $281 \quad$ Fruit and Seed Set. Bot Rev 60:83-139

282 Burnham KP, Anderson DR (2004) Multimodel inference: understanding AIC and BIC in model

283 selection. Sociol Method Res 33:261-304

284 City of Edmonton (2009) Terwillegar Park concept plan study.

285 http://www.edmonton.ca/city government/projects redevelopment/terwillegar-park-

286 concept-plan-study.aspx. Accessed January 13, 2013

287 De Jong T, Batenburg JC, Klinkhamer PGL (2005) Distance-dependent pollen limitation of seed

288 set in some insect-pollinated dioecious plants. Acta Oecol 28:331-335

289 Ferrari SLP, Cribari-Neto F (2004) Beta regression for modeling rates and proportions. J Appl

290 Stat 31:799-815

291 Field DL, Pickup M, Barrett SCH (2012) Comparative analyses of sex-ratio variation in

292 dioecious flowering plants. Evol 67:661-672 
293 Hamer D (1996) Buffaloberry (Shepherdia Canadensis) fruit production in fire-successional bear 294 sites. J Range Manage 49:520-529

295 Hendrickson OQ, Burgess D (1989) Nitrogen-fixing plants in a cut-over lodgepole pine stand of 296 southern British-Columbia. Can J For Res 19:936-939

297 House, SM (1992) Population density and fruit set in three dioecious tree species in Australian 298 tropical rain forest. J Ecol 80:57-69

299 Humbert L, Gagnon D, Kneeshaw D, Messier C (2007) A shade tolerance index for common 300 understory species of northeastern North America. Ecol Indic 7:195-207

301 Kay QON, Lack AJ, Bamber FC, Davies CR (1984) Differences between sexes in floral 302 morphology, nectar production and insect visits in a dioecious species, Silene dioica. New $303 \quad$ Phytol 98:515 to 528

304 Khanizadeh S, Buszard D, Fanous MA, Zarkadas CG (1989) Effect of crop load on seasonal 305 variation in chemical composition and spring frost hardiness of apple flower buds. Can J $306 \quad$ Plant Sci 69:1277-1284

307 Klinkhammer GL, de Jong TJ, Linnebank LA (2001) Small-scale spatial patterns determine 308 ecological relationships: an experimental example using nectar production rates. Ecol Lett $309 \quad 4: 559-567$

310 Knight TM, Steets JA, Vamosi JC, Mazer SJ, Burd M, Campbell DR, Dudash MR, Johnston MO, 311 Mitchell RJ, Ashman T (2005) Pollen limitation of plant reproduction: pattern and process. $312 \quad$ Annu Rev of Ecol Evol Syst 36:467-497

313 Krebs CJ, Boonstra R, Cowcill K, Kenney AJ (2009) Climatic determinants of berry crops in the 314 boreal forest of the southwestern Yukon. Bot 87:401-408

315 Kunin WE (1993) Sex and the single mustard: population density and pollinator behavior effects 316 on seed set. Ecol 74:2145-2160 
317 LaRoi G, Hnatiuk RJ (1980) The Pinus contorta forests of Banff and Jasper National Parks: a

318 study in comparative synecology and syntaxanomy. Ecol Monogr 50:1-29

319 Lewis G (1990) Sex ratio, sexual dimorphism and population dynamics in the dioecious shrub

320 Shepherdia canadensis. Dissertation, University of Calgary

321 McCray-Batzli J, Zimpfer JF, Huguet V, Smyth CA, Fernandez M, Dawson JO (2004)

322 Distribution and abundance of infective, soilborne Frankia and host symbionts Shepherdia,

323 Alnus, and Myrica in a sand dune ecosystem. Can J Bot 82:700-709

324 Melser C, Klinkhamer PGL (2001) Selective seed abortion increases offspring survival in

325 Cynoglossum officinale (Boraginaceae). Am J Bot 88:1033-1040

326 Mosquin T (1971) Competition for pollinators as a stimulus for the evolution of flowering time.

327 Oikos 22:398-402

328 Nielsen SE, Munro RHM, Bainbridge E, Boyce MS, Stenhouse GB (2004) Grizzly bears and

329 forestry II: distribution of grizzly bear foods in clearcuts of west-central Alberta, Canada.

$330 \quad$ Forest Ecol Manag 199:67-82

331 Osunkoya, OO (1999) Population structure and breeding biology in relation to conservation in

332 the dioecious Gardenia actinocarpa (Rubiaceae)- a rare shrub of Northern Queensland

333 rainforest. Biol Cons 88:347-359

334 Rhoades C, Binkley D, Oskarsson H, Stottlemyer R (2008) Soil nitrogen accretion along a

335 floodplain terrace chronosequence in northwest Alaska: Influence of the nitrogen-fixing

336 shrub Shepherdia canadensis. Ecoscience 15:223-230

337 Somanathan, H, Borges RM (1999) Influence of exploitation on population structure, spatial

338 distribution and reproductive success of dioecious species in a fragmented cloud forest in

339 India. Biol Cons 94:243-256

340 Steffan-Dewenter I, Tscharntke T (1999) Effects of habitat isolation on pollinator communities

341 and seed set. Oecologia 121:432-440 
342 Stringer P, LaRoi GH (1970) The Douglas-fir forests of Banff and Jasper National Parks, Canada.

343 Can J Bot 48:1703-1726

344 Wang J, Zhang C, Zhao X, Gadow KV (2013) Limitations to reproductive success in the

345 dioecious tree Rhamnus davurica. PLoS ONE 8(12): e81140.

346 doi:10.1371/journal.pone.0081140 


\section{Figure 1}

Canada buffaloberry flowers and fruit.

(A) Pistillate flowers, (B) staminate flowers and (C) ripe fruit of Canada buffaloberry (Shepherdia canadensis). Flowers photographed on 6 May 2009 and fruit on 8 July 2004 at Terwilleger Park, Edmonton, Alberta. Male shrubs begin flowering first (sometimes up to 1 week) and are 2 to 3 times larger than female flowers. Photographs by S. Nielsen. 


\section{Table 1 (on next page)}

Range and mean number of buffaloberry individuals within each scale of measurement.

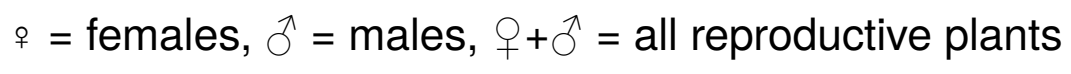




\begin{tabular}{|c|c|c|c|c|c|c|c|c|c|}
\hline \multirow[b]{3}{*}{ Range } & \multicolumn{3}{|c|}{$25 \mathrm{~m}^{2}$} & \multicolumn{3}{|c|}{$50 \mathrm{~m}^{2}$} & \multicolumn{3}{|c|}{$100 \mathrm{~m}^{2}$} \\
\hline & $\hat{\sigma}+q$ & $q$ & $\hat{0}$ & $\hat{\sigma}+q$ & q & $\hat{0}$ & $\hat{o}+q$ & q & $\hat{0}$ \\
\hline & $0-13$ & $0-8$ & $0-7$ & $0-24$ & $0-15$ & $0-13$ & $0-34$ & $0-20$ & $0-17$ \\
\hline $\begin{array}{c}\text { Mean } \\
(\mathrm{SE})\end{array}$ & $\begin{array}{c}3.3 \\
(0.44)\end{array}$ & $\begin{array}{c}1.7 \\
(0.26)\end{array}$ & $\begin{array}{c}1.60 \\
(0.23)\end{array}$ & $\begin{array}{c}6.22 \\
(0.78)\end{array}$ & $\begin{array}{c}3.43 \\
(0.46)\end{array}$ & $\begin{array}{c}2.78 \\
(0.39)\end{array}$ & $\begin{array}{l}10.42 \\
(1.20)\end{array}$ & $\begin{array}{c}5.58 \\
(0.68)\end{array}$ & $\begin{array}{c}4.83 \\
(0.58)\end{array}$ \\
\hline
\end{tabular}




\section{Table 2 (on next page)}

List of candidate models (hypotheses) predicting fruit set in buffaloberry based on demographic factors and scale of measurement. 


\begin{tabular}{|c|c|c|c|}
\hline ID & Hypothesis & Scale & Model \\
\hline 0 & Null (mean fruit set) & N.A. & \\
\hline 1 & Nearest male (simple pollen donor) & $N . A$. & $-\hat{O}_{\text {dist }}$ \\
\hline $1 \mathrm{a}$ & Nearest male \& size of nearest male & N.A. & $-\hat{O}_{\text {dist }}+\hat{O}_{\text {size }}$ \\
\hline $2 \mathrm{a}$ & Nearest male \& female competitor & 25 & $-\hat{O}_{\text {dist }}-q_{D_{25}}$ \\
\hline $2 b$ & Nearest male \& female competitor & 50 & $-\widehat{O}_{\text {dist }}-q_{D_{s} 0}$ \\
\hline $2 \mathrm{c}$ & Nearest male \& female competitor & 100 & $-\hat{O}_{\text {dist }}-q_{D_{1 ю 0}}$ \\
\hline 3 & Nearest female (simple pollen competitor) & $N . A$. & $+q_{\text {dist }}$ \\
\hline $4 a$ & Nearest female \& pollen donor & 25 & $+q_{\text {dist }}+\hat{O}_{D_{2 s}}$ \\
\hline $4 \mathrm{~b}$ & Nearest female \& pollen donor & 50 & $+q_{d i s t}+\hat{O}_{D s o}$ \\
\hline $4 \mathrm{c}$ & Nearest female \& pollen donor & 100 & $+q_{d i s t}+\widehat{O}_{D \text { Don }}$ \\
\hline $5 a$ & Density dependence & 25 & $+D_{25}$ \\
\hline $5 b$ & Density dependence & 50 & $+D_{50}$ \\
\hline $5 c$ & Density dependence & 100 & $+D_{100}$ \\
\hline $6 a$ & Pollen donor & 25 & $+\hat{O}^{\lambda}{ }_{2 s}$ \\
\hline $6 b$ & Pollen donor & 50 & $+\hat{O}_{D s 0}$ \\
\hline $6 c$ & Pollen donor & 100 & $+\hat{O}_{\text {Dюо }}$ \\
\hline $7 \mathrm{a}$ & Female competitor & 25 & $-q_{D_{25}}$ \\
\hline $7 b$ & Female competitor & 50 & $-q_{D^{s o}}$ \\
\hline $7 \mathrm{c}$ & Female competitor & 100 & $-q_{D \text { เo }}$ \\
\hline $8 \mathrm{a}$ & Pollen donor \& competitor & 25 & $+\hat{O}_{D s s}-q_{D 2 s}$ \\
\hline $8 b$ & Pollen donor \& competitor & 50 & $+\hat{O}_{D s 0}-Q_{D s 0}$ \\
\hline $8 \mathrm{c}$ & Pollen donor \& competitor & 100 & $+\hat{O}_{D 100}-q_{D ю 0}$ \\
\hline $9 a$ & Pollen donor $\mathrm{x}$ competitor (sex ratio) & 25 & $+\hat{O}_{D 2 s} *-q_{D 2 s}$ \\
\hline $9 b$ & Pollen donor $\mathrm{x}$ competitor (sex ratio) & 50 & $+\hat{O}_{D s o} *-q_{D s o}$ \\
\hline $9 \mathrm{c}$ & Pollen donor $\mathrm{x}$ competitor (sex ratio) & 100 & $+\hat{O}_{D 100} * q_{D 100}$ \\
\hline
\end{tabular}




\section{Table 3 (on next page)}

Ranking of support among candidate models using Akaike's Information Criteria adjusted for small sample size (AICc).

Hypothesis, model ID, scale (m2), model structure, parameter number (K), change in AICc and Akaike weights (wi) are provided. The line within the table separates models ranked higher than the null hypothesis (mean fruit set) from those ranked lower and are thus considered unrepresentative. 


\begin{tabular}{|c|c|c|c|c|c|c|c|}
\hline ID & Hypothesis & Scale & Model & $K$ & $\mathrm{AIC}_{\mathrm{c}}$ & $\Delta \mathrm{AIC}_{\mathrm{c}}$ & $w_{i}$ \\
\hline $8 \mathrm{~b}$ & Pollen donor \& competitor & 50 & $+\hat{O}_{D: 0}-q_{D: 0}$ & 4 & -51.7 & 0 & 0.244 \\
\hline $6 b$ & Pollen donor & 50 & $+\hat{O}_{D s 0}$ & 3 & -49.7 & 2 & 0.089 \\
\hline $8 \mathrm{c}$ & Pollen donor \&competitor & 100 & 1 & 4 & -49.6 & 2.2 & 0.083 \\
\hline $9 b$ & Pollen donor xcempetitor (sex ratio) & 50 & $+\hat{O}_{D s 0} *-q_{D s 0}$ & 5 & -49.5 & 2.2 & 0.08 \\
\hline 0 & Null $\quad \frac{\omega}{\partial}$ & N.A. & & 2 & -48.8 & 2.9 & 0.057 \\
\hline 1 & Nearest male (बimple pollen donor) & N.A. & $\overline{-\hat{O}_{\text {dist }}}$ & 3 & -48.2 & 3.5 & 0.043 \\
\hline $6 a$ & Pollen donor $\sum$ & 25 & $+\hat{O}_{D_{2 s}}$ & 3 & -48.2 & 3.5 & 0.043 \\
\hline $8 a$ & Pollen donor \&competitor & 25 & $+\hat{O}_{D 2 s}-q_{D 2 s}$ & 4 & -47.9 & 3.8 & 0.036 \\
\hline $6 c$ & Pollen donor $\overline{\bar{z}}$ & 100 & $+\hat{O}_{D_{10}}$ & 3 & -47.6 & 4.1 & 0.031 \\
\hline $4 b$ & Nearest female \& pollen donor & 50 & $+q_{\text {dist }}+\hat{O}_{D s}$ & 4 & -47.4 & 4.3 & 0.029 \\
\hline $9 \mathrm{c}$ & Pollen donor xcompetitor (sex ratio) & 100 & $+\hat{O}_{D 100}^{1} *-q_{D 100}$ & 5 & -47.3 & 4.5 & 0.026 \\
\hline $5 b$ & Density dependence & 50 & $+D_{50}$ & 3 & -47.1 & 4.7 & 0.024 \\
\hline $5 a$ & Density dependence & 25 & $+D_{25}$ & 3 & -46.8 & 4.9 & 0.021 \\
\hline $2 \mathrm{c}$ & Nearest male female competitor & 100 & $\widehat{O}_{\text {dist }}-Q_{D_{\text {Doo }}}$ & 4 & -46.6 & 5.1 & 0.019 \\
\hline $7 \mathrm{c}$ & Female comp t tor & 100 & $-q_{D \text { เюо }}$ & 3 & -46.6 & 5.1 & 0.019 \\
\hline $5 \mathrm{c}$ & Density dep $n$ dence & 100 & $+D_{100}$ & 3 & -46.6 & 5.1 & 0.019 \\
\hline 3 & Nearest female (simple pollen competitor) & N.A. & $+q_{\text {dist }}$ & 3 & -46.6 & 5.1 & 0.019 \\
\hline $7 b$ & Female competitor & 50 & $-q_{D s 0}$ & 3 & -46.5 & 5.2 & 0.018 \\
\hline $7 \mathrm{a}$ & Female competitor & 25 & $+\hat{O}_{D 2 s}$ & 3 & -46.5 & 5.2 & 0.018 \\
\hline $2 b$ & Nearest male \& female competitor & 50 & $-\widehat{O}_{\text {dist }}-Q_{D s o}$ & 4 & -46.4 & 5.3 & 0.017 \\
\hline $2 \mathrm{a}$ & Nearest male \& female competitor & 25 & $-\hat{O}_{\text {dist }}-Q_{D_{2 s}}$ & 4 & -46.2 & 5.5 & 0.015 \\
\hline $4 a$ & Nearest female \& pollen donor & 25 & $+q_{d i s t}+\hat{O}_{D 2 s}$ & 4 & -45.9 & 5.8 & 0.013 \\
\hline $9 a$ & Pollen donor $\mathrm{x}$ competitor (sex ratio) & 25 & $+\hat{O}_{D 25}^{1} *-q_{D 25}$ & 5 & -45.9 & 5.8 & 0.013 \\
\hline $1 \mathrm{a}$ & Nearest male \& size of nearest male & N.A. & $-\hat{O}_{\text {dist }}+\hat{O}_{\text {size }}$ & 4 & -45.9 & 5.9 & 0.013 \\
\hline $4 \mathrm{c}$ & Nearest female \& pollen donor & 100 & $+q_{\text {dist }}+\hat{O}_{D 100}$ & 4 & -45.2 & 6.5 & 0.01 \\
\hline
\end{tabular}




\section{Table 4(on next page)}

Model parameters and predicted total response in proportion fruit set for the top $\mathrm{AIC}_{\mathrm{C}}$ selected model.

Model coefficients $(\beta)$ for variables included in the most supported $\left(\right.$ AIC $_{c}$ ) candidate model describing fruit set in buffaloberry as the pollen donor and pollen competitor hypothesis (50 $\mathrm{m}^{2}$ scale). Change in the predicted dependent variable when the explanatory variable changes from its minimum to maximum value (while holding other factors at their mean value) is reported as $\Delta$ Min to Max. Note that flower index was used to represent total flower production (total sub-sample of flowers on shrub $\mathrm{X}$ shrub size) and was included as a covariate in all models ( $\beta$ reported here as 1000 times its real value given its absolute effect per flower index is small). 


\begin{tabular}{|c|c|c|c|c|c|c|}
\hline \multirow[b]{2}{*}{ Variable } & \multirow[b]{2}{*}{$\beta$} & \multirow[b]{2}{*}{$\mathrm{SE}$} & \multicolumn{2}{|c|}{$95 \%$ Conf. Interval } & \multicolumn{2}{|c|}{$\Delta$ Min to Max } \\
\hline & & & Lower & Upper & Coef. & $\mathrm{SE}$ \\
\hline$\hat{O}_{D 50}$ & 0.114 & 0.041 & 0.035 & 0.194 & 0.352 & 0.123 \\
\hline$q_{D 50}$ & -0.073 & 0.035 & -0.143 & -0.004 & -0.221 & 0.080 \\
\hline Flower index & -0.179 & 0.076 & -0.327 & -0.031 & -0.283 & 0.065 \\
\hline Constant & 0.510 & 0.152 & -0.808 & -0.213 & & \\
\hline
\end{tabular}




\section{Figure 2}

Sex bias of the most supported model.

Proportion fruit set predicted for buffaloberry based on female and male shrub density.

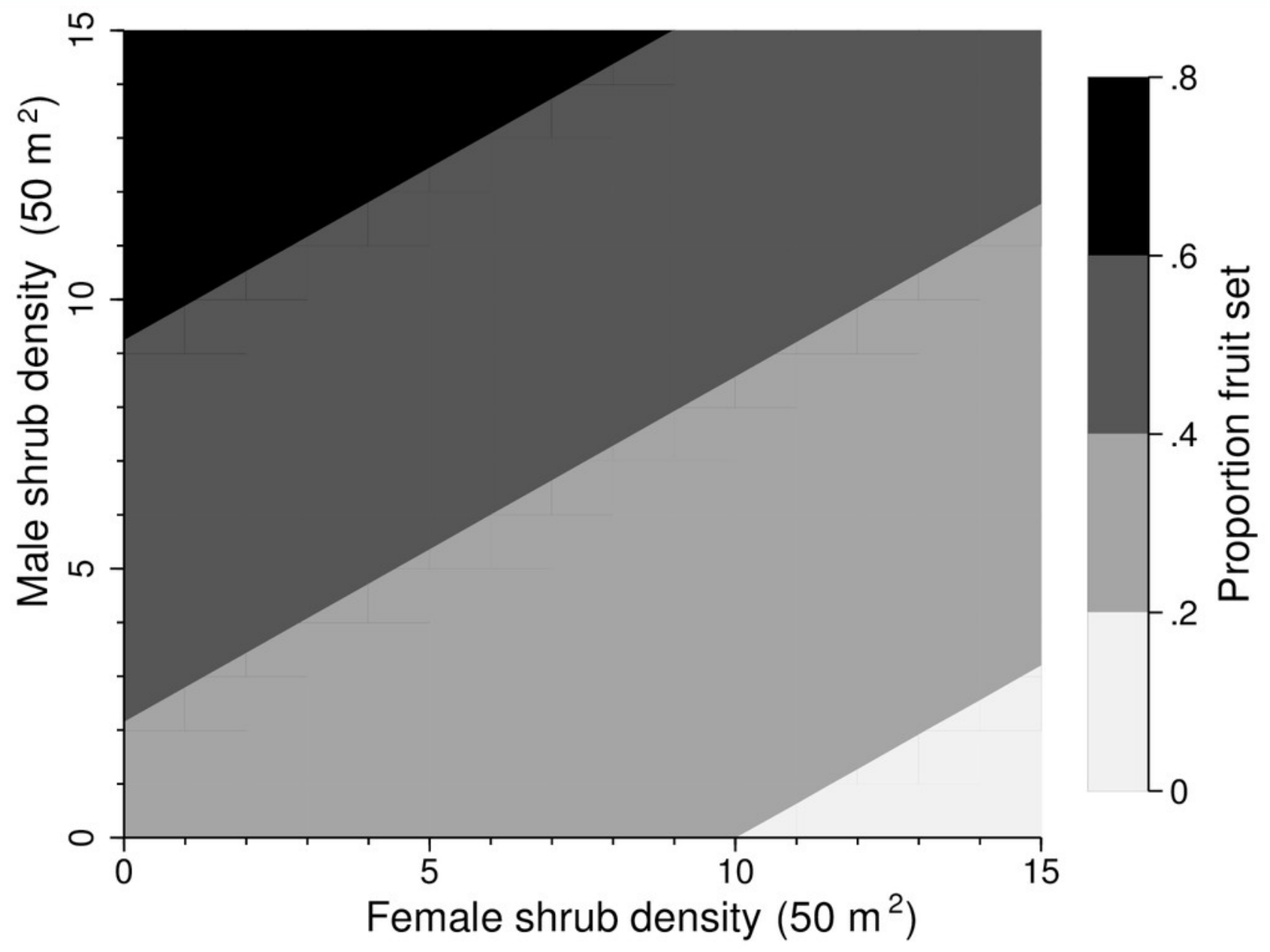

